\title{
Synthesis of Polypyrrole-coated $\mathrm{NiO} / \mathrm{Ni}(\mathrm{OH})_{2}$ Hybrid Flowers Composite by Pulse Electro-polymerization for supercapacitor with Improved Electrochemical Capacitance
}

\author{
Ji Yan ${ }^{1, *}$, Serubbabel Sy ${ }^{2}$, Heng Wang ${ }^{1}$, Yong Zhang ${ }^{1, *}$, Ai-Ping Y $^{3}$, Li-Zhen Wang ${ }^{1, *}$, Li-Ming Zhou ${ }^{1}$ \\ ${ }^{1}$ School of Material and Chemical Engineering, Henan Provincial Key Laboratory of Surface Interface \\ Science, Zhengzhou University of Light Industry, Zhengzhou 450001, Henan, China \\ ${ }^{2}$ Department of Chemical Engineering, Waterloo Institute for Nanotechnology, Waterloo Institute for \\ Sustainable Energy, University of Waterloo, Canada \\ *E-mail: jiyan@zzuli.edu.cn, wlz@zzuli.edu.cn
}

doi; $10.20964 / 2020.12 .68$

Received: 1 February 2020 / Accepted: 21 September 2020 / Published: 31 October 2020

This work describes a novel strategy to synthesize polypyrrole-coated $\mathrm{NiO} / \alpha-\mathrm{Ni}(\mathrm{OH})_{2}$ hybrid flower with an improved capacitance performance for supercapacitor. Polypyrrole nanoparticles with a size of 80-100 $\mathrm{nm}$ were prepared by a pulse electro-polymerization and uniformly embedded into the petal gap of the self-assembled $\mathrm{NiO} / \alpha-\mathrm{Ni}(\mathrm{OH})_{2}$ hybrid flower. Due to the enhancement of the electrical conductivity and the improvement of electrochemical pseudo-capacitance, the as-synthesized polypyrrole-coated $\mathrm{NiO} / \alpha-\mathrm{Ni}(\mathrm{OH})_{2}$ hybrid flower composite showed a high reversible specific capacity of $359 \mathrm{~F} \mathrm{~g}^{-1}$ at $5 \mathrm{~A} \mathrm{~g}^{-1}$ in $2 \mathrm{M} \mathrm{KOH}$ electrolyte in a potential range of $0-0.45 \mathrm{~V}$. Benefiting from the unique electro-polymerization design, the obtained hybrid flower composite demonstrated excellent capacitive performance and cycling stability after 1000 cycles, demonstrating the promising application as a high-performance pseudocapacitive material for supercapacitors.

Keywords: Supercapacitors, Polypyrrole, Hybrid flower, Pulse electro-polymerization

\section{$\underline{\text { FULL TEXT }}$}

(C) 2020 The Authors. Published by ESG (www.electrochemsci.org). This article is an open access article distributed under the terms and conditions of the Creative Commons Attribution license (http://creativecommons.org/licenses/by/4.0/). 